\title{
El impacto de la actividad extractiva petrolera en el acceso al agua: el caso de dos comunidades kukama kukamiria de la cuenca del Marañón (Loreto, Perú)
}

\section{Claudia V. Grados Bueno}

Pontificia Universidad Católica del Perú

\section{Eduardo M. Pacheco Riquelme}

Pontificia Universidad Católica del Perú

\section{RESUMEN}

En esta investigación nos aproximamos a las consecuencias de las actividades petroleras en el acceso a recursos naturales e hídricos en dos comunidades nativas kukama kukamiria, en la cuenca del rio Marañón (Loreto). Se analiza también el rol del Estado y las empresas involucradas en los derrames de petróleo ocurridos en la zona. Con dicho propósito, visitamos las comunidades de Shapajilla y Parinari, donde se realizaron entrevistas, talleres y observación participante. En este sentido, si bien los derrames han generado trasformaciones en el acceso y uso de agua (por ejemplo, en la calidad y cantidad del agua y peces que hay en la zona), se observa que la pesca y el río siguen siendo relevantes para el ecosistema, economía familiar y cosmovisión kukama. No obstante, la concepción de un entorno contaminado sigue generando incertidumbre en la población.

Palabras clave: recurso hídrico, pueblos indígenas, río Marañón, petróleo, Amazonía, actividad extractiva, kukama kukamiria. 


\section{Oil extractive activity's impact on access to water: The case of two Kukama Kukamiria communities of the Marañón river basin (Loreto, Perú)}

\section{ABSTRACT}

This research will try to address the consequences of oil extraction on the access to natural and water resources, especially in two native communities of the Kukama Kukamiria people located in the lower Marañon basin. Furthermore, we analyze the role of the state and enterprises involved in the oil spills occurred in the area. In this sense, even if the oil spills have transformed the access and use of water (for instance the quantity and quality of water and fish in the area) the river and fishing remain relevant for the ecosystem, family economy and Kukama cosmovision. Nonetheless, the conception of a polluted environment continues to create uncertainty in the population.

Keywords: water resources, indigenous people, Marañón River, oil, Amazonia, extractive industry, Kukama Kukamiria. 


\section{INTRODUCCIÓN}

Diferentes estudios hablan de la organización del riego en poblaciones indígenas con sistemas autoorganizados y autogobernados, con diferentes niveles de eficiencia en el gobierno del agua (Mitchell y Guillet, 1994, en Trawick, 2001, p. 2). La escasez del agua y la forma de enfrentarla en comunidades campesinas altoandinas y costeñas son puntos claves en esta discusión. No obstante, queda pendiente entender la compleja situación de la Amazonia, donde el recurso hídrico es comprendido y usado de diferentes maneras.

El agua en la Amazonía es un «entramado de drenajes de diferente orden y magnitud» (Bernal, 2006, p. 12) que representa la riqueza hídrica de la zona. Sin embargo, su calidad se ve afectada por la actividad extractiva y los desechos urbanos que contaminan los cuerpos de agua, aspectos que junto al cambio climático podrían producir un proceso de estrés hídrico a futuro (2006, p. 15). Por ello, nos parece importante ahondar en la relación entre agua y población amazónica, con el objetivo de analizar los impactos de las actividades petroleras en el acceso a recursos hídricos en dos comunidades nativas kukama kukamiria en la cuenca del río Marañón (Loreto).

\section{CICLO HIDROSOCIAL DEL AGUA}

Según Orlove y Caton (2010), desde la antropología el agua no se considera solo como un recurso, sino como una sustancia que conecta diferentes esferas de la vida social gracias a su valoración, su distribución y sus reglas. Debido a esta conectividad, los autores plantean entender al agua como un hecho social total que tiene dimensiones materiales moldeadas por su relación con el cuerpo humano, ambiente y otras estructuras hechas por el hombre (2010, p. 403), circulando por casi todos los dominios de la vida social rural y urbana (Swyngedouw, 2004; Swyngedouw et al., 2002, en 2010, p. 403). 
Esta conectividad nos permite entender el ciclo del agua como un ciclo hidrosocial en el que se conjugan los componentes físicos, sociales, económicos, políticos y culturales de manera intrínseca (Swyngedouw, 2006 en 2009, p. 56). Este ciclo se origina desde diferentes tipos de valoración del recurso que variarán según el espacio y las construcciones sociales (Limbert, 2001, en 2010, p. 404). Por ejemplo, Arrieta (2010) ha tratado de entender las representaciones sociales del agua en los matsiguengas del Bajo Urubamba, resaltando la importancia del sistema fluvial para dichos pueblos en sus prácticas cotidianas y sobrevivencia (p. 216). Al ser un «elemento vital» (higiene, transporte) y a la vez una fuente de recursos (p. 226), el agua se articula con el «entorno social» y permite repensar el ciclo hidrológico también en el ámbito cultural (pp. 204-205). Asimismo, resalta cómo los usos simbólicos y culturales del agua — principalmente reflejados en sus mitos (p. 213) — se ven transformados por procesos de titulación de tierras, la valoración económica de las empresas petroleras en procesos de negociación con comunidades y los procesos de urbanización llevados a cabo (p. 201).

Así, el agua puede ser valorada de diferentes maneras: puede considerarse como un recurso natural que permite la actividad productiva o como un derecho humano (Arrieta, 2010; Johnston, 2003, p. 74). Asimismo, puede ser valorada de forma positiva (sobrevivencia, higiene, placer) o negativa (inundaciones, erosiones, riesgos o enfermedades).

Este proceso no deja de ser político, ya que se basa en los derechos y obligaciones de cada uno de los actores involucrados (Swyngedouw, 2009). Este punto va de la mano con la equidad en el acceso y distribución del agua (Orlove y Caton, 2010, p. 404). De hecho, el valor del agua moldea políticas que no necesariamente aseguran un acceso justo de los diferentes grupos sociales según clase, etnia, género o edad (Arrieta, 2010; Swyngedouw, 2009, p. 57). De esta manera, son algunos actores los que tienen un poder de decisión efectivo, mientras que otros se quedan al margen, pero siguen siendo afectados (Boelens y Doornbos, 2001; Derman y Ferguson, 2003, en Arrieta, 2010, p. 405).

Uno de los actores claves es el Estado (Swyngedouw, 2006, p. 18) a través de intervenciones hidráulicas — represas, canales, etc. - en las que se necesita una fuerte inversión de capital (Arrieta, 2010, p. 23). Sin embargo, este va perdiendo la autoridad y el monopolio del poder ante la presencia del sector privado y la sociedad civil (ONG, organizaciones de riego, etc.) como formas de gobernanza alternativas (Tropp, 2007, p. 26). 
Por ello, los actores involucrados buscan diferentes estrategias de acción que consideren sus puntos de vista y necesidades, viendo políticamente el manejo del agua y balanceando demandas que parecen contradictorias, como la doméstica, agrícola o industrial (Orlove y Caton, 2010, p. 408). En este contexto, el reto sería entender si la distribución y organización del ciclo hidrosocial se puede desarrollar de una manera más efectiva y democrática (Swyngedouw, 2009, p. 59), puesto que el control no solo depende de quién tiene el agua sino de la calidad, tipo, volumen y organización que está detrás de esta (Arrieta, 2010). Como menciona Rose (2003), es necesario considerar los cambios que atraviesa el recurso al pasar por un sistema que puede verse afectado por «la contaminación biológica y química de la agricultura, industria y vida urbana» (2003, p. 74).

\section{HIDROCARBUROS EN LA AMAZONIA}

Esta contaminación se vio facilitada por el fomento estatal y privado a proyectos extractivos. Tal como menciona Surrallés, a la par que el Estado permitía el proceso de titulación de las comunidades nativas, tenía una política favorable a grandes inversiones de extracción de recursos, que, si bien eran rentables para el gobierno, terminaban perjudicando a los pueblos indígenas a través de impactos ambientales y sociales (2011, p. 404). La industria petrolífera es un caso emblemático de ese fenómeno.

La problemática de los ríos de la Amazonia ha sido desarrollada en primera instancia desde un enfoque físico-biológico sobre la bioecología de los peces en las cuencas de los ríos Ucayali y Marañón (Tello y Montreuil, 1992). Asimismo, encontramos estudios sobre el impacto de los metales pesados en los peces de mayor consumo en esta zona (Bendayán, 1992; Marques et al., 2013). Estos estudios marcan un parámetro importante respecto de los efectos concretos en el ecosistema y en las personas, pero también deben ser analizados junto a otros que nos permitan entender los efectos sociales de estos procesos. Así, son relevantes las investigaciones del pueblo Achuar en la cuenca del río Corrientes (Chirif, 2010) y de los Kichwa del Pastaza (La Torre, 1998) donde se denuncian los efectos en la salud de los pobladores, la degradación del río y quebradas cercanas. A esto se ha sumado el caso de los kukama kukamiria del río Marañón, que se encuentran en una situación similar (Rodríguez, 2014).

Al hablar de contaminación, Isch recalca el efecto que tiene sobre la cantidad, calidad, formas de distribución y acceso al recurso hídrico (2011, p. 97). En este proceso, los discursos que fomentan la modernización y el desarrollo a través 
de políticas neoliberales valoran el agua a un nivel estrictamente económico, excluyendo las creencias y prácticas indígenas sobre la diversidad de valoraciones que hemos mencionado en la sección anterior (Boelens y Gelles, 2005; Getches, 2005). Si bien en el caso de los hidrocarburos el agua no es un insumo más para la producción, sigue siendo afectada en el proceso, considerando que el Estado no termina de cumplir con su rol regulador.

La actividad petrolera en la parte baja de la cuenca amazónica comenzó en la década de 1920, y la explotación incrementó a finales de los años sesenta a partir del descubrimiento del Lote $1 \mathrm{AB}$ - actualmente 192 - por la empresa pública Petroperú en el distrito de Trompeteros, en la cuenca del río Corrientes (Okamoto, 2011).

Durante la década de 1970 e inicios de los ochenta esta producción representó un ingreso importante para la economía peruana; sin embargo, a mediados de la década de 1980 la exploración y producción decayó (Dourojeanni, 2013). A partir de 2000 la actividad petrolera reflotó, y en la actualidad se encuentran en explotación cuatro lotes. Los principales son el 192, administrado por Pacific Stratus Energy (512 347,24 ha) y el Lote 8 (182 348,21 ha) a cargo de Pluspetrol Norte (Perupetro, 2015).

Como podemos ver en el mapa 1, hay cerca de treinta lotes de hidrocarburos, de los cuales veintiuno están en exploración (Perupetro, 2014). En la actualidad, la producción del Lote 8 se transporta por un ducto hacia el sur hasta la Estación 1 en San José de Saramuro, una parte es conducida por el Oleoducto Nor Peruano hacia la Refinería de Talara en la costa de Piura o para su exportación desde el puerto de Bayóvar (Dourojeanni, 2013).

Tal como se observa en el mapa 1, el Lote 8 está repartido en varias zonas a lo largo de la cuenca de los ríos Corrientes, Chambira y Marañón. Otra parte de su producción sale de la comunidad nativa San José de Saramuro (Marañón) por vía fluvial en barcazas tanque con el fin de ser procesada en la refinería de Iquitos, cuyo combustible atiende la demanda de esta ciudad, de Yurimaguas, Tarapoto y de sus respectivos aeropuertos.

En los más de cuarenta años de explotación petrolera en los lotes 192 y 8 han sucedido diversos incidentes que han dañado a las comunidades que viven alrededor del río. El año 2000 se produjo un derrame en el Bajo Marañón de aproximadamente 5000 barriles de petróleo, originado cerca de la comunidad nativa San José de Saramuro (Okamoto, 2011, p. 66), debido al hundimiento de una barcaza transportadora de crudo. A partir de este suceso, las comunidades nativas iniciaron un proceso de reorganización en asociaciones y federaciones para poder defender su territorio. 
Mapa 1. Lotes en exploración en la región Loreto

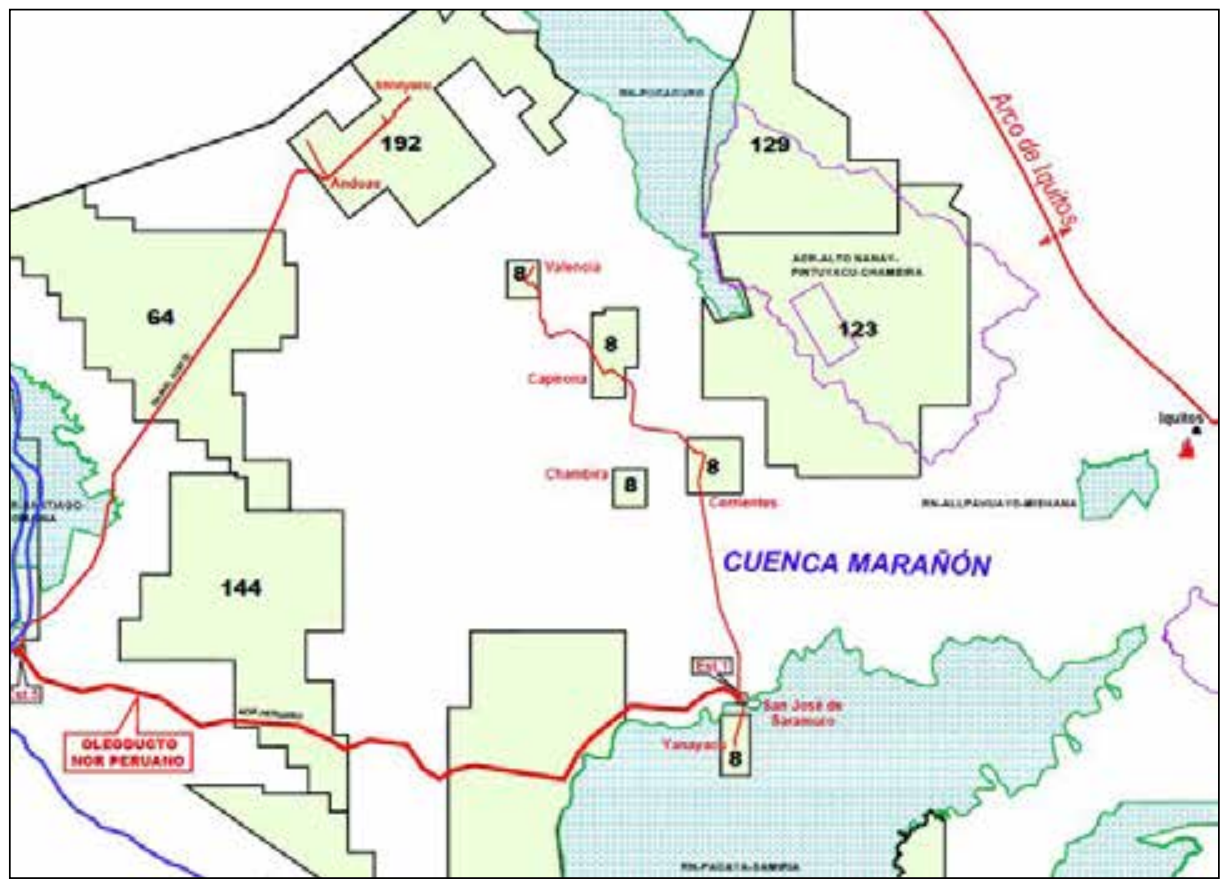

Fuente: Perupetro (2014).

Una de las organizaciones que lidera el proceso es Acodecospat (Asociación Cocama de Desarrollo y Conservación San Pablo de Tipishca).

Nuevamente, el 19 de junio de 2010 se produjo un derrame en la base de Pluspetrol por razones similares. La empresa señaló que se derramaron 374 barriles. Estos cubrieron el área desde Saramuro hasta Santa Rita de Castilla, e incluso se vieron en la ciudad de Nauta. Además, la población informó que al día siguiente la empresa usaba una sustancia blanca - material orgánico llamado Grodarban - para aglomerar y hundir el crudo (Okamoto, 2011, p. 62).

A partir de 2012 se inició el trabajo en conjunto entre las organizaciones de las cuatro cuencas afectadas por derrames (Corrientes, Pastaza, Tigre y Marañón), unión con la que se logró la reactivación de la Comisión Multisectorial para mejorar su situación social y ambiental, a cargo de la Presidencia del Consejo de Ministros (PCM, 2012). Desde las federaciones indígenas se exigió realizar exámenes a la calidad del agua y niveles de contaminación en peces y humanos como un primer paso hacia la declaratoria de emergencia sanitaria y ambiental. 
La comisión debía durar un año y entregar informes cada tres meses sobre los avances. Sin embargo, a mediados de 2013 su plazo de funcionamiento se extendió por un año más debido a la compleja situación de las cuatro cuencas. Hasta ese momento solo se había logrado la declaratoria de emergencia del río Pastaza tras un monitoreo ambiental (PCM, 2012). Es en este año cuando se hacen los estudios de calidad de agua, suelos y sedimentos en las cuencas del Marañón y Tigre, cuyos resultados indicaron los altos niveles de metales pesados como plomo, cadmio y arsénico en el suelo y agua (OEFA, 2014). Si bien se realizaron diferentes planes de acción y la Comisión volvió a instaurarse bajo el nombre de Comisión Multisectorial para el Desarrollo de las Cuencas del Pastaza, Tigre, Corrientes y Marañón (PCM, 2014), la carencia de medidas concretas llevó a la población kukama a organizar medidas de protesta que reclamaron la presencia del presidente Ollanta Humala, incluyendo la gran marcha kukama o wita ritama en junio de 2014.

\section{EL PUEBLO KUKAMA KUKAMIRIA DEL BAJO MARAÑÓN}

Los kukama kukamiria pertenecen al tronco lingüístico tupí guaraní, y su proceso migratorio empezó hace más de ochocientos años (Berjón y Cadenas, 2014, p. 2). Su centro de expansión fue entre el río Paraguay y el Paraná, hacia la costa amazónica del Atlántico (Ramos, 1944, p. 62, en Agüero, 1994, p. 5), desde donde emigraron para ubicarse en zonas del Alto Amazonas, y el Bajo Huallaga, Ucayali, Pastaza y Marañón (Rivas, 2004, en Okamoto, 2011, p. 23). Si bien no se tienen datos precisos, se estima una población de alrededor de 85000 personas, tanto en espacios urbanos como rurales (Okamoto, 2011, p. 23; Chirif y Mora, 1975, p. 122, en Agüero, 1994, p. 6).

A lo largo de su historia han sido subordinados por diferentes agentes externos que han incentivado modificaciones en su organización social y residencia. Así, entre 1535 y 1820 fueron organizados en haciendas y reducciones para trabajar en los cultivos o el servicio doméstico a cambio de educación, protección y evangelización (Agüero, 1994, p. 54). También se formaron misiones donde tuvieron su primera aproximación a la fe católica y empezaron a desarrollar actividades más sedentarias (1994, p. 55).

En 1768, cuando los misioneros jesuitas fueron expulsados de las colonias españolas, los kukama kukamiria quedaron expuestos a los patrones y comerciantes de los ríos (regatones), incorporándose como subalternos a un sistema de explotación económica a cambio principalmente de herramientas (San Román, 1975, p. 91 
en Agüero, 1994, p. 58). A través de este proceso, se empezaron a crear nuevas ciudades y poblados que se articularon también de forma subordinada durante la época de la extracción de caucho, entre 1880 y 1914. Cuando esta terminó, los kukama kukamiria se reagruparon en sus territorios ancestrales ribereños, bajo el patrón de caseríos (Agüero, 1994, pp. 62 y 69). Con el inicio de la explotación de petróleo, en 1970, se reubicaron y empezaron a trabajar como peones en centros urbanos (Rumrill-Zutter, 1976, en Agüero, 1994, p. 64).

En la actualidad, gran parte de su organización social y económica proviene de este proceso histórico, donde la agricultura también se alzó como una actividad importante, siendo las zonas de várzea en las riberas de los ríos las que resultaban más atractivas para su desarrollo (Agüero, 1994, p. 41). Por otra parte, la pesca siguió siendo una actividad clave que brindaba acceso a proteínas y al mercado (Rivas, 2004, p. 15), debido a su cercanía al río (Tessman, 1999, en Rivas, 2004). Así, a través de cientos de años la población kukama kukamiria ha reforzado su conocimiento sobre el medio ambiente acuático y su ciclo hidrológico, y ha desarrollado diferentes técnicas e instrumentos para sus usos y prácticas (Rivas, 2004, p. 26). Esto se vincula con el alto valor social que se brinda a la pesca por sobre la caza, además de ser resaltada en sus mitos de origen y en la memoria colectiva de la población (Girard, 1958, en Rivas, 2004, p. 27).

En este sentido, el agua también está íntimamente ligada a su cosmovisión, puesto que los mundos se clasifican en tres espacios: la tierra, el cielo y el mundo del agua. En este último habitan diferentes seres, como el yacuruna, la sirena, los bufeos, y además la gente que vive dentro del agua. En este espacio, el tiempo pasa de una manera más lenta, pero hay vida (Berjón y Cadenas, 2014, p. 4). Además, gran parte de estos seres son considerados «madres del agua» — es decir, la razón de existencia de este recurso-- por lo que su desaparición también es motivo de preocupación constante para una población que tiene al río como fuente principal de agua, de peces y de un valor simbólico que se ha visto amenazado por los eventos explicados anteriormente. 


\section{DOS COMUNIDADES KUKAMA KUKAMIRIA} EN EL DISTRITO DE PARINARI

«De eso vivimos, bañamos, alimentamos, lavamos las otras cosas. Por eso nosotros decimos que el agua es muy importante para nosotros. Por eso es que hasta ahorita seguimos defendiendo» (comunero kukama de Shapajilla, 52 años, 13 de julio de 2014).

Tratando de comprender mejor el acceso, uso y gestión del agua en las comunidades kukama kukamiria en la cuenca del Bajo Marañón después de los derrames de petróleo, visitamos las ciudades de Iquitos y Nauta, y luego las comunidades nativas Shapajilla y Parinari —ubicadas en el distrito del mismo nombre - del 29 de junio al 11 de agosto de 2014 (ver mapa 2). Estas comunidades se encuentran localizadas aproximadamente a cinco horas de la ciudad de Nauta.

\section{Mapa 2. Comunidades nativas del Bajo Marañón}

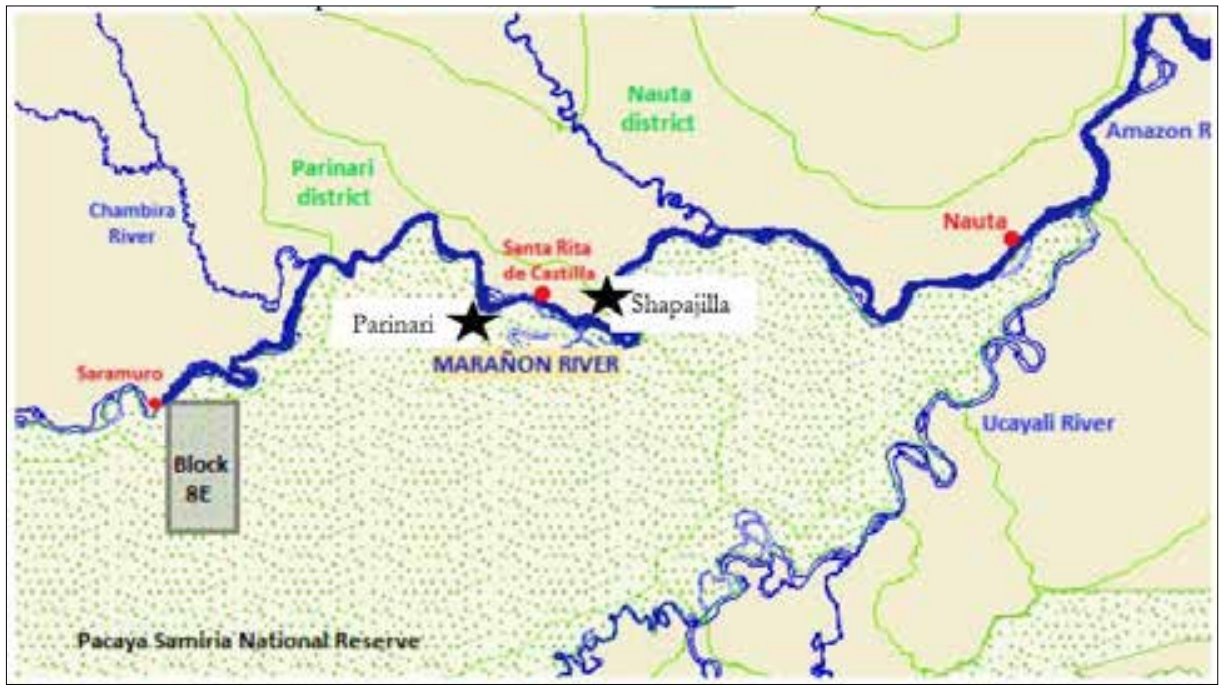

Fuente: Okamoto (2011).

La información fue obtenida a través de entrevistas semiestructuradas a miembros de veintidós unidades domésticas en la comunidad de Shapajilla y 26 en Parinari, además de ser complementadas mediante la observación participante de la pesca, el trabajo agrícola, la recolección de agua, el proceso de aseo, lavado de ropa, actividades de entretenimiento en el río y la quebrada, transporte fluvial, 
entre otros. De forma tangencial se realizaron calendarios ecológicos en talleres con alrededor de veinte participantes, y mapas comunales con las autoridades principales ${ }^{1}$. A partir de la información obtenida explicaremos la memoria de los derrames y las actividades productivas de la zona, mientras que en los siguientes capítulos trataremos de entender el acceso, uso y estrategias de consumo de agua antes, durante y después de los derrames.

\section{Recuento histórico: barrancos y migraciones}

La comunidad nativa de Shapajilla está compuesta por veintisiete familias y en sus más de cien años de existencia se ha caracterizado por un proceso de migración frecuente a diferentes lugares de la cuenca. Esto se debe al desbarrancamiento de tierra generado por las lluvias - fenómeno conocido como barranco-, que los ha obligado a movilizarse constantemente. En el caso de Parinari ${ }^{2}$ encontramos una comunidad con cuarenta familias que también se han reubicado debido al barranco que se llevó anteriormente casas y veredas.

Según el director de la escuela primaria de Shapajilla, dentro de los márgenes del terreno anterior se llegaron a movilizar alrededor de diez veces, porque el barranco destruía sus locales. Esto afectó los campos de cultivo al inundar los productos: «los víveres de panllevar se perdían cada año» (director de primaria de comunidad nativa de Shapajilla). Incluso la cocha (laguna) de la que se proveían de alimentos también fue destruida por la fuerza del río. De esta manera, el barranco generaba gran incertidumbre en la población.

En la comunidad nativa de Parinari, el barranco los está obligando a reubicar sus casas cada vez más lejos del río. Según nos contaron los pobladores, antes «el río quedaba lejos, no estaba tan cerquita como ahora, antes no se veía al Marañón, sino tenías que ir caminando, ahí lo veías; ahora está acá nomás» (comunero de Parinari, 36 años, 1 de agosto de 2014). Según las autoridades, la comunidad cuenta con un plan de reubicación que especifica los futuros lotes para las casas y los centros educativos, la cancha de fútbol y el local comunal.

Regresando a Shapajilla, la actual comunidad tiene alrededor de veinte años de creación. El terreno pudo conseguirse gracias al apoyo de habitantes de Santa Rita de Castilla, debido al requerimiento de las autoridades comunales.

\footnotetext{
En ambos casos participaron el apu, el teniente gobernador y el agente municipal; solo en Parinari se incluyó también al juez de paz.

2 Cabe mencionar que Parinari se encuentra ubicado en la intersección entre la quebrada del mismo nombre y el río Marañón.
} 
Sin embargo, fue este proceso de movilización el que llevó a gran parte de la población a migrar. Diferentes pobladores señalan que el antiguo Shapajilla era un pueblo grande con mucha población, pero después del barranco un grupo se fue a diferentes cuencas ${ }^{3}$.

\section{Actividades productivas: agricultura y pesca}

Las principales actividades que se desarrollan en la zona son la agricultura y la pesca. En ambas situaciones, como menciona Agüero, sus cultivos pueden ser utilizados para el autoconsumo familiar - yuca o plátano principalmente- o para la venta: arroz, maíz, nuevamente el plátano, camote, otras hortalizas y menestras; los cuales son complementados por otros productos que se adquieren en el comercio local (1994, p. 70).

Por otra parte, la pesca es la base de la alimentación de la comunidad, más aún cuando los animales del monte se alejan cada vez más. Por ello, tanto hombres como mujeres aprenden a diferentes edades, la mayoría desde muy pequeños observando, pero también hay mujeres cuyas parejas les enseñaron. A veces son los hombres los que van de madrugada o en la noche a pescar, pero en el día pueden ir en familia como parte de una actividad de entretenimiento, sobre todo los fines de semana. Asimismo, cuando van en parejas suele ser la mujer la que rema, mientras que el varón va colocando la red donde entrarán los peces ${ }^{4}$.

Si bien en teoría hay un horario fijo para estas actividades, la situación está sujeta a cambio según el clima, distancia u otras responsabilidades. Por ejemplo, en el caso de Shapajilla, el principal lugar de pesca es el río; a veces van a las cochas que están a dos horas de la comunidad, o si no, entran a la Reserva Nacional Pacaya Samiria con permisos de ocho días. En cambio, en la comunidad de Parinari la quebrada y las cochas son los lugares principales de pesca. Es precisamente entre julio y septiembre - cuando el agua desciende - cuando aparecen más peces (período llamado mijano).

3 Es necesario recalcar que en los últimos años tanto la migración temporal como la permanente han aumentado, sobre todo entre los jóvenes, que se van por motivos educativos o laborales a ciudades como Iquitos o Lima. Durante nuestra estadía muchos de los varones que estuvieron trabajando en Lima durante 2013 estaban retornando a sus casas.

4 De hecho, no es extraño que las mujeres sepan remar, considerando que el río los comunica con el resto de comunidades. 


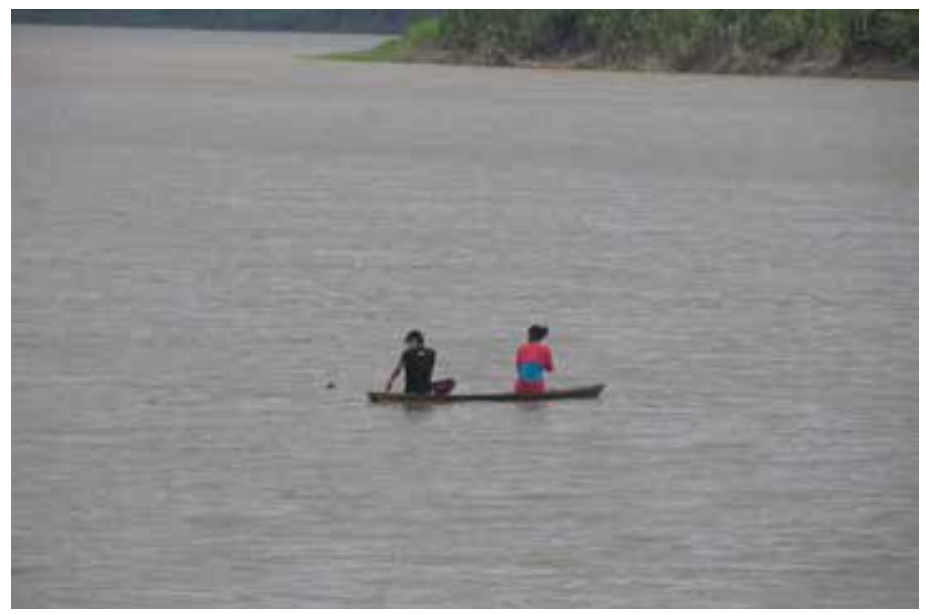

Foto 1. Pareja colocando una trampa en el río Marañón, comunidad nativa de Shapajilla. Foto: Eduardo Pacheco.

\section{Recuento de los derrames}

Bajo estas condiciones de asentamiento, sucedieron los derrames de petróleo en las comunidades. Si bien tanto en Shapajilla como en Parinari no todos los entrevistados han determinado la fecha exacta, se marcan dos etapas importantes: la primera alrededor de 2000 y la segunda alrededor de 2010. Los comuneros coinciden en que en ambas ocasiones el río se llenó de petróleo, de manera que no tenían de dónde sacar agua en ese momento, sobre todo porque la empresa no avisó con anticipación que el petróleo podía llegar a sus comunidades:

Salimos de esta isla al río y todito el ancho del río nos damos cuenta que era negro. Yo metía mi pie y me daba cuenta que en mis pies se pegaba negro, negro. Y me paro así del bote y veo negro todito, señorita, todo el ancho del río. Y la gente de Santa Rita ya estaba alarmada, totalmente alarmada. Todito el día, tremendas planchas, ¡negro de verdad! (comunero de Shapajilla, 55 años, 15 de julio de 2014).

Todita la quebrada era así brillante el agua, bien brillante, y cuando salía al río el agua chocaba; allá al río se hacía así despacito, negro salía. Y por eso decían que estaba bien contaminado [...] los palos, señorita, la palizada, eran bien negros, negro color de esas botas eran los palos, la misma tierra de donde choca el agua ahí ha quedado bien negro; ellos han puesto gente para que junten esos palos (comunero de Parinari, 43 años, 28 de julio de 2014). 
La población recuerda que el petróleo era muy espeso o «doble» y que dejaba sus rastros en las orillas del río. En este contexto, comentan que los representantes de la empresa llegaron días después, cuando el crudo ya no era evidente, por lo que no les creyeron que el derrame hubiera llegado a su comunidad. Por eso tuvieron que mostrarles el petróleo que habían recogido en envases y los restos que había en palizadas, gramalotes y otras plantas de las orillas. Al comprobarlo, iniciaron el proceso de limpieza superficial:

Y eso le venían a juntar la gente. No creía, no creía. Pero la gente no era zonza, así le han juntado el petróleo. Deja en balde para que le hagan ver a los que venían a mirar el agua, «este del petróleo que ustedes no creen, nosotros le hemos juntado para que ustedes vean» (comunera kukama de Shapajilla, 46 años, 16 de julio de 2014).

Se ha venido diciendo que el petróleo se ha derramado. Buscaban en los yates, a la caminata, viajaban por el Marañón buscando el petróleo. Yo le he dicho que había derrame. Cuando la gente comenzó a saber, recién ya ellos se han enterado que hay derrame de petróleo (comunero de Parinari, 43 años, 2 de agosto de 2014).

Si bien en el primer derrame hubo reclamos, las comunidades nativas no llegaron a articularse para difundir sus demandas. Vendría a ser el derrame de 2010 el que motivó este impulso. Un punto que generó gran preocupación en esta época fue el uso de «polvos blancos» que los representantes de la empresa empezaron a echar en el río, para juntar el petróleo y hundirlo5. Si bien parecía desaparecer ante sus ojos, la población tenía claro que seguía circulando en las profundidades, por lo que podía reaparecer:

La empresa empezó a soltar unos polvos para que sumerjan el petróleo. Al tercer día ya no quedaba nada, decían que ya está limpio, pero tú recogías el agua siempre quedaba con brillo. Todo lo que estaba sumergido tenía que reflotar (comunero kukama de Shapajilla, 4 de julio de 2014).

Han traído a su gente y han bajado todo usando química, un polvo como blanco que tiraban al río y sumía el petróleo; ya no le veíamos porque estaba al fondo, ya no se veía nada, pero el agua quedaba brillosa (comunero de Parinari, 72 años, 25 de julio de 2014).

Es ante este derrame que se dan las negociaciones entre las comunidades del distrito de Parinari y la misma Pluspetrol, que llega a ofrecer S/. 1500 por familia,

5 Esta sustancia orgánica se llama Grodarban. 
aunque les descontaron $\mathrm{S} / .150$ correspondientes a los tanques de agua con filtro entregados por la empresa. Asimismo, en ambos casos Pluspetrol dio víveres y agua. Lamentablemente estos a veces no fueron suficientes y la población tuvo que volver a consumir el agua y los peces del mismo río.

[Sobre los alimentos] pero eso era por una temporadita nomás, unos meses creo era que ha dado agua San Luis, después alimentos [...] Una época nomás, pero bien poquito $[. .$.$] y luego nos han dado una propina a todas las$ comunidades nativas, han sido beneficiadas con una plata, con una platita de 1400 soles por morador (comunera kukama de Parinari, 2 de agosto de 2014).

En ambos derrames los peces se vieron afectados en cantidad y calidad: por un lado, no era tan viable encontrarlos, y cuando los encontraban sus escamas parecían de jebe, estaban flacos y cabezones, no tenían sabor, e incluso encontraron petróleo en las agallas de algunos:

En 2000 no había tanto pescado en el río, difícil se encontraba pescado. Algunos, con el petróleo se ha muerto. Había unos peces así, cahuara como dicen. Ese tiempo hacía como un año que no había ese peje, ese pescado (comunero kukama de Shapajilla, 39 años, 15 de julio de 2014).

Que cuando ha habido ese derrame los pescados se han hecho bien flacos, flaquitos. Tremendos pescados, así como el boquichico, de este gruesito, su cabecita flaquito, sus escamitas se hacían como si tuviera un tumor así en su carne. Bien feo, ¡cómo va comer esos pescados! (comunera kukama de Shapajilla, 46 años, 16 de julio de 2014).

Debido a esto, la venta de pescado también se vio afectada. A pesar de ser una actividad que no se realiza a gran escala, representaba un ingreso eventual en las familias. Sin embargo, en esa época la población de otras localidades ya no quería comprar pescado de la zona y prefería consumir el de las cochas.

Por ello, la pesca para las comunidades kukama se encuentra en constante transformación. A pesar del tiempo transcurrido, la cantidad de peces es menor, de manera que se requiere más tiempo y esfuerzo para conseguir especies que antes se encontraban con facilidad. Esto los obliga a quedarse con los primeros pescados que encuentren, cuando antes podían incluso escoger las especies que más les apetecían.

Ahora vamos a coger puritita carachama para comer, ahora vamos mañana para agarrar zúngaro en el canto de la playa y agarrábamos tarrafeando ${ }^{6}$. La gente escogía si quería comer su boquichico, su sardina, su corvina, su palometa, su lisa, su fasaco, su acarahuasu, su bujurqui, escogía. Y ahora no

6 Técnica de pesca utilizando una red llamada tarrafa. 
hay ni para escoger, peor para agarrar en cantidad [...]. Antes si era cantidad para que agarres, por canoadas, toneladas, así era antes (comunero kukama de Shapajilla, 52 años, 13 de julio de 2014).

Antes había mucho mijano, tú los escuchabas venir, sonaba como balas en la quebraba. Había doncella, zúngaros, incluso paiches había antes, era solo peces grandes, ahora solo pez chiquitito que tienen otro sabor. Ya no es como antes (comunero de Parinari, 43 años, 2 de agosto de 2014).

La razón de estos cambios aún no ha sido definida y por eso la población insiste en hacer exámenes ecotoxicológicos. No obstante, ellos tienen diferentes nociones sobre lo que está sucediendo con el pescado y consideran al petróleo como una de las principales causas que también habría afectado el uso y acceso a agua a través del tiempo.

\section{Acceso y uso del agua antes y durante los derrames}

Si bien el río y la quebrada siempre han sido una fuente importante de agua, en las comunidades se han observado diferentes iniciativas - tanques de agua construidos por Cáritas, piletas o caños y el tanque municipal— que previamente les permitieron conseguir este recurso de forma más directa en la última década. No obstante, al momento de realizar el trabajo de campo ninguna de estas iniciativas estaba en funcionamiento.

El proyecto más exitoso fue un sistema de tratamiento de agua hecho por Cáritas poco antes de 2000, que bombeaba el agua de río hacia cuatro tanques elevados, para posteriormente pasar por un proceso de filtración (arena, carbón, etc.). Luego era tratada con cloro y otras sustancias. De este proceso se obtenía agua que los comuneros definen como «linda», «limpia», «buena» y similar al agua de lluvia.

A pesar de que no funcionaba todo el año — con la sequía los tubos no llegaban al margen del río y con lluvias muy fuertes estos podían obstruirse- - se recuerda con mucha satisfacción su funcionamiento, ya que les permitía ahorrar la caminata al río, sobre todo para conseguir agua útil para la cocina o para beber; el lavado de ropa, utensilios y el baño diario seguían haciéndose en el río. Posteriormente tuvieron problemas para mantener los tubos y los filtros; en Shapajilla estos últimos requerían de alumbre y cal, pero la comunidad no tenía recursos para colaborar. De esta manera, el proyecto duró entre ocho y diez años, pero es un claro referente de los sistemas que desean tener a futuro. El mismo modelo de proyecto fue implementado en la comunidad de Parinari y funcionó sin problemas entre tres y cinco años, hasta que se malogró el motor que bombeaba agua. 


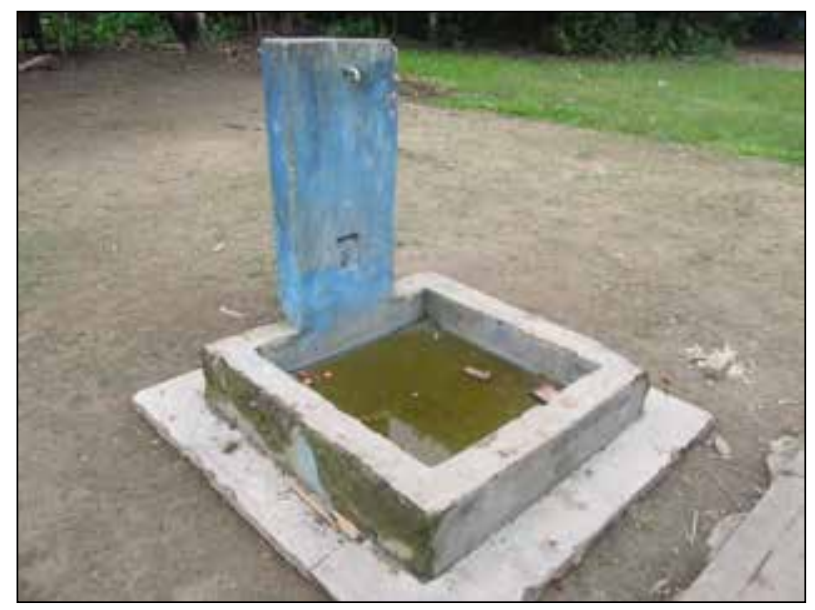

Foto 2. Pileta, comunidad nativa de Shapajilla. Fuente: Eduardo Pacheco.

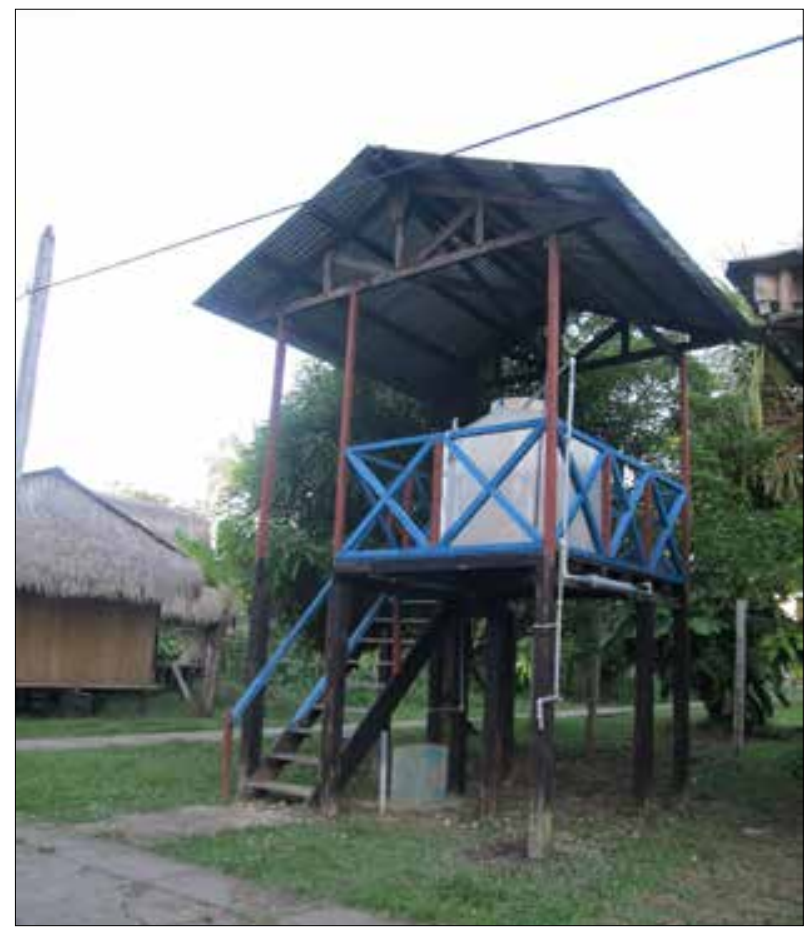

Foto 3. Tanque municipal, comunidad nativa de Parinari. Fuente: Eduardo Pacheco. 
El último proyecto fue un tanque hecho por la municipalidad distrital en 2014 (foto 4), que tampoco se encuentra en funcionamiento. En general, se observa que, a pesar de estos intentos, el río (Shapajilla) o la quebrada (Parinari) no dejan de estar en uso, sino que cumplen un rol igual de relevante o complementario. No obstante, durante la época de los derrames se presentaron algunas variaciones.

\section{Estrategias de acceso a agua durante los derrames}

Parte de los comuneros entrevistados en Shapajilla mencionaron que en esas épocas la opción más inmediata era seguir tomando agua de río. Esto se lograba moviendo la primera capa de petróleo que estaba en la superficie, para acceder al agua que se encontraba debajo. Sin embargo, los comuneros no sabían que usar el agua de esta manera podría generarles daños mayores: «Cuando el río iba bajando y no había agua teníamos que limpiarlo así nada más. No sabíamos que nos podía contaminar o dañar» (teniente gobernador de Shapajilla, 46 años, 16 de julio de 2014).

Si bien durante los primeros días del derrame no se usaba el agua de río, con el paso del tiempo - y al ver que el agua brindada por la empresa no alcanzaba para bañarse, lavar los utensilios o la ropa - tuvieron que acudir al Marañón o a la quebrada más cercana. Por otro lado, diferentes familias usaban agua de lluvia en la medida de lo posible, pero esto dependía de la frecuencia e intensidad de las precipitaciones. No obstante, para purificar el agua las familias optaban por echarle cloro, lejía o hervirla.

En la comunidad de Parinari la situación fue similar. A pesar de ubicarse en una quebrada, durante los derrames el petróleo entró y cubrió sus aguas. Según contó una comunera: «un día, como a las dos de la tarde habrá sido, me dijo mi mamá "vaya a acarrear agua", voy yo. [...] me voy, total veo una cosa negra, negro, señorita, todito el canto de la orilla de donde está el agua, los árboles, caña brava mira así ve» (comunera de Parinari, 39 años, 1 de agosto).

Al igual que las familias en Shapajilla, tuvieron que utilizar agua que les brindó la empresa durante un breve tiempo; luego no les quedó más opción que usar el agua de la quebrada. «Nosotros tomábamos agua de la quebrada, clorada, cocinada tomábamos el agua y así la tomábamos, así la tomábamos, clorada, cocinada, no la tomamos así nomás» (comunero de Parinari, 39 años, 28 de julio).

Es importante recordar que la situación fue fluctuante, ya que el petróleo no desaparecía por completo. En el río, algunos comuneros vieron planchas de petróleo que reaparecían según la variabilidad del nivel de agua, situación que duró por aproximadamente dos meses. 


\section{Acceso y uso del agua ahora}

En Shapajilla, la principal fuente de agua es el río, para algunos como fuente única $\left(10 / 21^{7}\right)$ y para otros en conjunto con el agua de lluvia (10/21). Esta situación se perpetúa sobre todo ante la carencia de otras fuentes más inmediatas: «Qué se hace pues señorita, si no tenemos de dónde más para sacar el agua. Tenemos que tomar, pues esa agua, si no ¿de dónde más? No hay ni cochas, no hay quebradas aquí. Cuando llueve así se junta agua. Y a veces un mes no llueve tienes que tomar agua del río» (comunera kukama de Shapajilla, 44 años, 13 de julio de 2014). En Parinari la fuente principal es la quebrada (26/26); a diferencia de Shapajilla, pocas familias usan el agua de lluvia (3/26) y ninguna usa agua del río. Incluso varios nos mencionaron que cuando tienen que ir a ver sus cultivos, en la otra orilla del Marañón, llevan agua de la quebrada en botellas o preparan refresco.

Otro factor a considerar es la diferencia de acceso entre época seca y de lluvia. La primera suele desarrollarse entre agosto y octubre, para luego dar paso a las lluvias desde enero. De esta manera, en época seca es necesario ir a recoger agua desde muy temprano para no ser afectados por el sol: «Ahí es más complicado, señorita, ahí tengo que madrugar para cargar nuestra agua. Primero tengo que acarrear el agua y recién ir a la chacra, porque cuando duele el sol, la playa caldea» (comunera kukama de Shapajilla, 28 años, 19 de julio). En Parinari, el nivel del agua también varía según la temporada: en verano, «el agua corre mucho y baja con hojas y bastante maleza, hay que asentarla antes de usarla» (comunero de Parinari, 74 años, 30 de julio).

En época de invierno es posible usar agua de lluvia, que algunos consideran más limpia. Esta se recolecta de diferentes maneras; principalmente se coloca un plástico que permite que el agua resbale con más facilidad a los envases donde será almacenada. Las casas que tienen calamina también hacen uso de esta técnica.

Si bien estas son las fuentes naturales de agua utilizadas por la población kukama de forma tradicional, todas reciben un tipo de tratamiento según los recursos que tenga la población. En el caso del agua de río en Shapajilla, la principal forma de tratamiento es asentarla por un tiempo determinado (18/21), aspecto que puede combinarse con el uso paralelo de cloro (11/21) o alumbre $(11 / 21)$. Solo una minoría elige otras opciones, como hacerla hervir, usar lejía o limón $(1 / 21)$. En el caso del agua de quebrada de Parinari, la mayoría asienta el agua $(20 / 26)$ y en menor cantidad usan cloro para tratarla $(15 / 26)$.

\footnotetext{
7 De los veintidós casos obtenidos, solo veintiuno respondieron esta sección.
} 


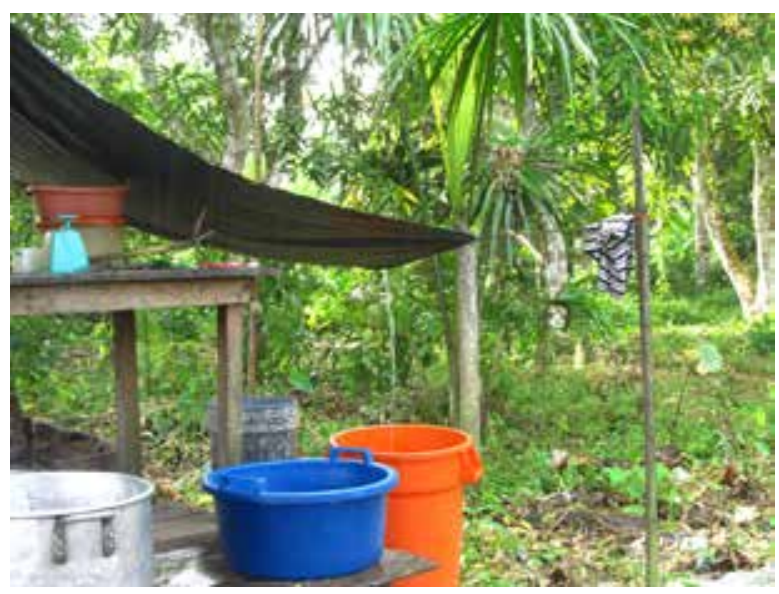

Foto 4. Recolección de agua de lluvia. Fuente: Eduardo Pacheco. Lugar: comunidad nativa de Shapajilla.

A continuación, brindamos los detalles de cada proceso:

Tabla 1. Tipos de tratamiento para aguas de río y lluvia

\begin{tabular}{|c|c|}
\hline Mecanismo & Descripción \\
\hline $\begin{array}{l}\text { Proceso de } \\
\text { asentar }\end{array}$ & $\begin{array}{l}\text { Es la medida más inmediata: se llena un balde con agua y se espera } \\
\text { durante unas horas, aunque a veces puede ser toda la noche. Esto } \\
\text { permite que todo el polvo se quede en la base del balde, para } \\
\text { posteriormente pasar el agua que está en la superficie a otro envase. }\end{array}$ \\
\hline Cernir & $\begin{array}{l}\text { Se pasa el agua de un envase a otro colocando una tela que } \\
\text { aglomerará todos los residuos. }\end{array}$ \\
\hline Uso de cloro & Se colocan unas gotas de cloro, y luego se espera dos horas. \\
\hline Uso de alumbre & $\begin{array}{l}\text { Suele usarse en forma sólida. Al ponerse en el agua se gira sesenta } \\
\text { veces en una misma dirección. Esto permite que en unos treinta } \\
\text { minutos el agua se asiente y se pase a otro balde. }\end{array}$ \\
\hline Uso de lejía & $\begin{array}{l}\text { Se echa unas gotas al agua, pero no se especifica la cantidad; puede } \\
\text { ser de forma paralela con el cloro. }\end{array}$ \\
\hline Hervir & $\begin{array}{l}\text { Solo una familia mencionó que hierve el agua para beber. En caso } \\
\text { que el agua se use para cocinar, el proceso de hervirla está implícito. }\end{array}$ \\
\hline
\end{tabular}

Elaboración propia sobre la base de información recolectada en trabajo de campo. 
El agua es clave para el desarrollo de actividades familiares, de manera que ir a recogerla es lo primero que se hace al despertar, alrededor de las 6 a.m. A lo largo del día, el agua servirá para diferentes propósitos que figuran en el diagrama 1. Cada uno de estos usos sociales puede desarrollarse con agua de río, quebrada o lluvia, según la época del año.

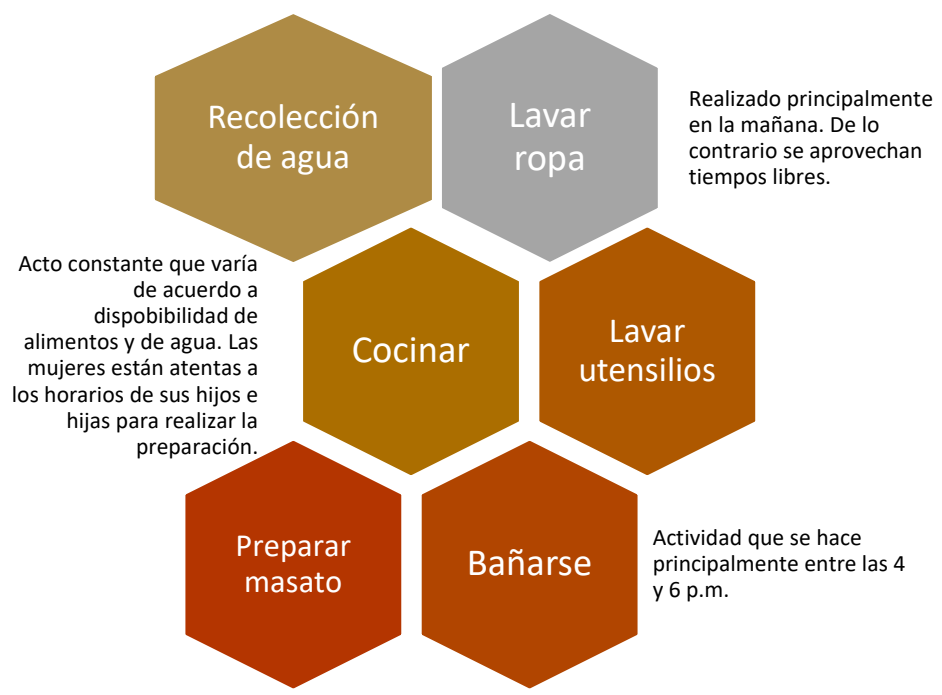

Diagrama 1. Principales actividades desarrolladas con agua

Como vemos en el diagrama, todas las actividades mencionadas son claves para la sobrevivencia de la población. De esta manera, el agua es un recurso importante a ser protegido, y el río o la quebrada son espacios con los que se interactúa siguiendo ciertas reglas. Así, la recolección de agua es una tarea que pueden realizar tanto hombres como mujeres; sin embargo, estas últimas deben tener cuidado al acercarse a ciertas horas, sobre todo al mediodía o muy de noche, ya que en esos momentos suelen aparecer los bufeos u otros espíritus del agua.

Yo me quería bañar, estaba toda sudada, ya eran las nueve de la noche [...] Yo he bajado y ahí nomás he sentido un aire en todo mi cuerpo. Me he bañado, me he desvestido, $[\ldots] \mathrm{Y}$ en eso empieza, parece que me rodea un viento [...] cuando he sentido el viento he sentido frío y un aire caliente que le pasa a mi cuerpo. «Ay, no», le digo. He venido a dormir y ya estaba soñando que estoy andando en un bote, y estábamos con mi mamá. [...] Total, señorita, para qué, estoy soñando [...] Yo me sentía como loca, sentía que no tengo cabeza. [...]. Me quería levantar, no podía respirar (comunera de Parinari, 39 años, 1 de agosto de 2014). 
En ciertas ocasiones serán también los niños o niñas los que se encarguen de las actividades mencionadas en el diagrama 1, según su disponibilidad de tiempo o presencia en la casa. En las entrevistas, la mayoría señala que todos ayudan (pareja o familia extensa) en la recolección, pero durante nuestra estadía vimos que son las mujeres las que van constantemente al puerto a traer los baldes u ollas llenas de agua sobre sus cabezas, más aún en los casos de las mujeres cuyos esposos no se encontraban en ambas comunidades. La cantidad de viajes es aún más variable: prefieren ir al río una o dos veces en la mañana antes de que salga el sol, pero si el agua se acaba durante el día es necesario ir nuevamente: «Cuando el agua te falta tú te vas [...] Cuando te falta, está vacío el balde, tú te vas» (comunera kukama de Shapajilla, 44 años, 13 de julio de 2014).

\section{Percepción de contaminación y su efecto en el uso cotidiano}

«Eso de plomo en el pescado se sabía en Corrientes y Pastaza, pero no por acá, ahora estamos aprendiendo que acá también (médico vegetalista kukama, 21 de julio de 2014).

Antes del derrame de 2010 y los resultados brindados por la DIGESA especificando el grado de metales que tiene el agua del río Marañón, había poco interés por la población sobre la situación del agua: la incertidumbre y la desinformación primaban. Ahora, con estos resultados, la preocupación es constante, porque la información tampoco se ha dado de forma completa. Las comunidades kukama demandan exámenes físicos de la población y de los peces, para saber en qué grado ellos también poseen estos metales.

Ahora que hay conciencia de que el agua está contaminada, se manejan dos opciones. Por un lado, están las familias que han optado por consumir principalmente agua de lluvia, a pesar que el acceso a esta tampoco es frecuente; mientras que permanecen otras familias que continúan usando el agua de río (Shapajilla) y de quebrada (Parinari) porque consideran que no hay otra opción. Asimismo, considerando que los peces son su principal fuente de alimento y la relevancia de la pesca en estas comunidades, también se opta por seguir consumiendo los pescados a los que tienen acceso:

Teníamos que comerlos, si no que íbamos a comer; pensábamos que en la carne no estaba el petróleo, pero ya cuando han venido a examinar los técnicos se han dado cuenta de que estaba contaminado; nosotros comíamos, aunque sentíamos su sabor a combustible y echábamos la culpa a la cocinera (teniente gobernador de Shapajilla, 46 años, 16 de julio de 2014). 
Algunos pescados que agarras son medio flaquitos, flaquitos son los pescados. A veces hace daño también los pescados, parece que están gordos. No son gordos [...] no es porque están gordos los pescados, flaquitos están los pescados. Algunos pescaditos son gordos. Son también así sequitos, delgaditos. Esto pasa principalmente con los de río, los de la quebrada sí son gorditos (comunera de Parinari, 48 años, 29 de julio de 2014).

Queda claro que en ambas comunidades hay conciencia de que tanto el agua como los pescados están contaminados, pero dejar de consumirlos no necesariamente es una opción viable.

\section{A MODO DE CONCLUSIÓN}

Si bien hay mucho que decir aún sobre la relación entre la población kukama kukamiria y el agua que la rodea, en este artículo hemos tratado de esbozar la situación y estrategias que permiten su uso y acceso en dos comunidades específicas. La pesca y el uso del agua siguen siendo relevantes en niveles ecosistémicos, económicos y de la cosmovisión kukama; sin embargo, la contaminación es otro factor que se suma y transforma estos procesos. Así, si bien nos queda claro que los ecosistemas de la Amazonia son frágiles y que han sido construidos a través de varios milenios de ocupación (Descola, 2004, p. 220), se ven afectados por diferentes procesos extractivos fomentados por el Estado y por intervenciones privadas. El pueblo kukama es un ejemplo claro de este proceso.

Queda claro que la explotación y el transporte petrolero en la cuenca del Marañón han generado cambios en las actividades de las comunidades y su acceso a los recursos naturales. En el caso del agua, los derrames produjeron períodos de escasez de agua «limpia» o «clara»; a su vez, menguaron la cantidad y tipos de peces a los que las comunidades tienen acceso. Como se mencionó en los párrafos anteriores, los pescados que recogían los pobladores tenían las escamas machadas por el petróleo y su sabor era completamente diferente. Asimismo, los distintos tratamientos de agua que antes no eran necesarios (alumbre, cloro, etc.), se hacen cada vez más comunes, pero también dependen de los recursos económicos de una población que tiene a la agricultura y la venta de su propia mano de obra como fuente económica principal.

De esta manera, si bien el río y las quebradas fluyen, brindando acceso a diferentes personas, esta agua no necesariamente cumple con las características de calidad. En este contexto, por el Estado o la empresa no hay un interés claro en resolver los problemas relacionados con el agua y la contaminación que afectan 
a las poblaciones de la cuenca del Marañón, que sí depende de ella para subsistir. Más bien, es común escuchar diferentes declaraciones afirmando que los reclamos de los pueblos indígenas son un ejemplo de su oposición a todo tipo de desarrollo.

Hasta el momento, de parte del Estado y de los actores privados, el recurso hídrico sigue siendo valorado como un insumo para otras actividades económicas; si bien se puede reconocer que hay un derecho de acceso para la población kukama, este terminaría siendo de menor relevancia. Esta situación no es extraña a la experiencia histórica del pueblo kukama con otros grupos de poder (caucheros, regatones, etc.). Por ello, es importante resaltar nuevamente la relevancia de la conectividad del ciclo hidrosocial del agua (Orlove y Caton, 2010; Swyngedouw, 2009) que permite entender cómo este se relaciona con diferentes aspectos de la vida cotidiana de la población kukama de Shapajilla y Parinari.

En este sentido, ante la necesidad de recursos para subsistir, la población kukama sigue realizando sus actividades cotidianas en una constante incertidumbre sobre la contaminación en la que se encuentran inmersos, y en si el Estado o los actores privados prevendrán otras situaciones similares a futuro.

\section{Agradecimientos}

Este artículo se realizó gracias al apoyo del fondo NWO-WOTRO «The Transnationalisation of Local Water Battles» (Holanda). Un especial agradecimiento a las señoras Mariluz Canaquiri y Emilsen Flores (lideresas de la federación de mujeres Waynakana kamatahuara kana), a los padres Manolo Berjón y Miguel Ángel Cadenas, y a Leonardo Tello (Radio Ucamara) por todo su apoyo en todo el proceso.

\section{REFERENCIAS BIBLIOGRÁFICAS}

Agüero, Óscar (1994). El milenio en la Amazonía peruana: Mito y utopía tupí-cocama o la subversión del orden simbólico. Lima/Quito: Abya Yala/CAAAP.

Arrieta, N. (2010). Agua y sistema fluvial: entre los matsiguengas del Bajo Urubamba. En Lo colectivo y el agua: Entre los derechos y las prácticas (pp. 201-231). Lima: IEP, Concertación.

Bendayan, N. (1992). Determinación de metales pesados bioacumulables en especies ícticas de consumo humano en la Amazonía peruana. Folia Amazónica, 4(2), 171-181. 
Berjón, Manolo y Miguel Cadenas (2014). Inestabilidad ontológica». El caso de los kukama de la Amazonía peruana. OALA, Organización de Agustinos de Latinoamérica Área de Formación. Disponible en: http://sanagustin.org.pe/oala/ pdf/2014_15Manuel.pdf

Bernal, H. (2006) El agua de la Amazonía, recurso estratégico para la Comunidad Sudamericana de Naciones (Casa) en el siglo XXI. Trabajo presentado al X Jornadas de Economía Crítica, realizadas en Barcelona del 23 al 25 de marzo de 2006. Disponible en: http://pendientedemigracion.ucm.es/info/ec/jec10/

Boelens, R. y P. Gelles (2005). Cultural politics, communal resistance and identity in Andean Irrigation development. Bulletin of Latin American Research, 24(3), 311-327. https://doi.org/10.1111/j.0261-3050.2005.00137.x

Chirif, A. (2010). Los achuares del Corrientes: el Estado ante su propio paradigma. Antropológica, 28, 289-309.

Descola, Philippe (2004). Las cosmologías indígenas de la Amazonía. En Alexandre Surrallés y Pedro García Hierro (eds.), Tierra adentro: Territorio indígena y percepción del entorno (pp. 25-35). Copenhague: IWGIA.

Dourojeanni, Marc (2013) Loreto sostenible al 2012. Parte 1. Lima: Derecho, Ambiente y Recursos Naturales (DAR). Disponible en: http://pronaturaleza.org/wp-content/uploads/2013/Otras-Publicaciones/PDF-02.pdf

Getches, D. (2005). Defending indigenous water rights with the laws of a dominant culture: the case of the United States. En D. Roth, R. Boelens y M. Zwarteveen (eds,), Liquid Relations. Contested Water Rights and Legal Complexity (pp. 44-65). New Brunswick, NJ/Londres: Rutgers University Press.

Isch, E. (2011). La contaminación del agua como proceso de acumulación. En R. Boelens, L. Cremers y M. Zwarteveen (eds.), Justicia hídrica: acumulación, conflicto y acción social (pp. 97-109). Lima: IEP.

La Torre, L. (1998). ¡Solo queremos vivir en paz! Experiencias petroleras en territorios indígenas de la Amazonia peruana. IWGIA, 25.

Marques, R. C., J.V.E. Bernardi, J.G. Dórea, K.G. Brandão, L. Bueno, R.S. Leão, O. Malm (2013). Fish consumption during pregnancy, mercury transfer, and birth weight along the Madeira river basin in Amazonia. International Journal of Environmental Research and Public Health, 10(6), 2150-2163. https://doi. org/10.3390/ijerph10062150

Mauss, Marcel (1971). El ensayo del don. En Sociología y Antropología (pp. 154 -220). Madrid: Tecnos.

OEFA [Organismo de Evaluación y Fiscalización Ambiental] (2014). Resultados del monitoreo ambiental participativo en la cuenca del río Marañon - locación Yana- 
yacu y derecho de vía del oleoducto Yanayacu - Saramuro (Lote 8 - Pluspetrol Norte S.A.) [Diapositiva]. Consulta: 22 de octubre de 2015.

Okamoto Mendoza, Tami (2011). Enclave extraction and unruly engagements: Oil spills, contamination and the Cocama-Cocamilla indigenous people in the Peruvian Amazon. Oslo: Tesis de Maestria de Estudios en Desarrollo para Norwegian University of Life Sciences (UMB). Disponible en: http://brage.bibsys.no/ xmlui/bitstream/handle/11250/187802/3/Okamoto_2011.pdf

Orlove, Ben y Steven Caton (2010). Water sustainability: Anthropological approaches and prospects. Annual Review of Anthropology, 39, 401-415. https://doi. org/10.1146/annurev.anthro.012809.105045

Perupetro (2014). Mapa de Lotes petroleros. Disponible en: http://www.perupetro. com.pe/wps/wcm/connect/perupetro/site/Informacion\%20Relevante/Mapa\%20 de\%20Lotes/Mapa\%20de\%20Lotes. Consultado el 18 de marzo de 2015.

Perupetro (2015). Contratos en fase de explotación al 31.12.2015. Disponible en: http:/www.perupetro.com.pe/wps/wcm/connect/3641851e0ed1-491f-a5a3-9a20fa 7d8281/contratos+explotacion+diciembre+2015. pdf?MOD=AJPERES\&contratos\%20explotacion $\% 20$ diciembre $\% 202015$. Consultado el 5 de enero de 2016.

Presidencia del Consejo de Ministros (2014). Resolución Suprema 119-2014-PCM. Lima, 31 de marzo. Consulta 15 de octubre de 2014.

Presidencia del Consejo de Ministros (2012). Resolución Suprema 200-2012-PCM. Lima 29 de junio. Consulta 13 de octubre de 2014.

Rivas Ruiz, Roxani (2004). El gran pescador: técnicas de pesca entre los cocamacocamilla de la Amazonía peruana. Lima: PUCP.

Rodríguez, R. (2014). Los kukama kukamiria del Marañón y su lucha por una vida digna y saludable. Iquitos, CAAAP. Disponible en: http://caaap.org.pe/ web/index.php/using-joomla/extensions/components/content-component/ archived-articles/78-noticias/176-los-kukama-kukamiria-del-maranon-y-sulucha-por-una-vida-digna-y-saludable

Rose Johnston, Barbara (2003). The Political Ecology of Water: An Introduction. Capitalism Nature Socialism, 14(3), 73-90. https://doi.org/10.1080/10455750308565535

Rosengren, Dan (2004). Matsigenka. En F. Barclay y F. Santos, Guía etnográfica de la Alta Amazonía (pp. 1-157). Lima: IFEA.

Surrallés, Alexandre (2011). Antropología después de Bagua. Movimiento indígena, políticas públicas y conocimiento antropológico. En J.P. Chaumeil, O. Espinosa y N. Cornejo (eds.), Por donde hay soplo: Estudios amazónicos en los países andinos (pp. 397-421). Lima: PUCP, CAAAP, EREA -LESC. 
Swyngedouw, Erik (2006). Power, Water and Money: exploring the Nexus. Nueva York: United Nations Development Program.

Swyngedouw, Erik (2009). The Political Economy and Political Ecology of the HydroSocial Cycle. Journal of Contemporary Water Research \& Education, 142(1), 56-60. University Council of Water Resources. https://doi.org/10.1111/j.1936704X.2009.00054.x

Trawick, Paul W. (2001). Successfully Governing the Commons: Principles of Social Organization in an Andean Irrigation System. Human Ecology, 29(1), 125. https://doi.org/10.1023/A:1007199304395

Tello, J. y V. Montreuil (1992). Bioecología de los peces de importancia económica de parte inferior de los ríos Ucayali y Marañón. Folia Amazónica, 4(2), 87-107.

Tropp, Hakan (2007). Water gobernance: trends and needs for new capacity development. Water Policy, suplemento 2, 19-30. https://doi.org/10.2166/wp.2007.137 